\title{
Apuntes para una espiritualidad en tiempos de violencia. Reflexiones desde la experiencia salvadoreña*
}

\author{
Jon Sobrino, \\ Centro de Reflexión Teológica, San Salvador.
}

Me han pedido unas reflexiones sobre "espiritualidad en tiempos de violencia", $y$, aunque el tratamiento de la violencia es siempre difícil, es también necesario abordarlo, pues vivimos en un mundo sumamente violento. Para caer en la cuenta de ello no hay más que recordar los conllictos armados en Irak, Irán, Afganistán, Sud́f́rica, Tchad, Grenada, Panamá, Nicaragua, Guatemala, EI Salvador, Irlanda, Yugoslavia, Euskadi..., la mayoría de ellos, por cierto, acaecidos en el tercer mundo, y de los cuales varios persisten lodavía. Con modestia, pues, a la manera de "apuntes", con cierto "temor y temblor" y desde mi experiencia salvadorefla, vamos a abordar el tema. Pero antes me parece importante esclarecer el lugar y el talante de estas reflexiones.

a) El lugar de estas reflexiones es el conflicio salvadorefio, conflicto distinto al de Euskadi, pero semejante al de muchos otros países en el tercer mundo. En su origen está la negación injusta y masiva de la vida de las grandes mayorias, lo cual exigió después la violencia oficial para mantener los privilegios de unos pocos y origino la violencia revolucionaria de respuesta para transformar esa sinuación. Este es, pues, sólo un tipo de conflicto, pero cuantitativamente es el más extendido -en muchos lugares del tercer mundo- y cualitativamente es el más grave, pues su rấz está en la injusta negación de la vida Por ello, pensamos que la experiencia salvadorefla puede ser útil para iluminar el tratamiento -de forma más universal- del tema que nos han propuesto. En El Salvador, en efecto, se impone la pregunta de con qué espiritu se debe vivir un conlicto

- Conferencia pronunciena en Bilbeo, el 18 de febrero de 1993. Sobre el contaxto. véase ln introducción al artículo de José I. Gonzilez Faus. 
violento con toda su tragedia. Pero, recordémoslo, de all se puede aprender también que es posible poner fin a la violencia y terminar el conflicto de forma pacífica, negociada. Y por último alli se puede admirar la impresionante "nube de testigos", es decir, de mártires, que han querido revertir la violencia prefiriendo cargar con ella que ocasionarla.

Quisiera aclarar lambién que en el conflicto salvadoreño he visto mayor justicia y humanidad, en su conjunto, en la parte revolucionaria que en la oficial, pero eso no quita que no haya que analizar la violencia revolucionaria. $Y$ nos detendremos más en ella que en la del sistema, pues ésta es mucho mas fácil de analizar y juzgar en su terrible pecaminosidad, ya que proviene de la injusticia estructural, "violencia institucionalizada" como la llamó Medellín, y genera para perpetuarse- la violencia masiva y cruel de ejércitos, cuerpos de seguridad y escuadrones de la muene'.

b) Por lo que toca al talante, estas reflexiones son personales, consisten fundamentalmente en elevar a concepto el impacto que me ha causado la violencia en la vida real y la pregunta de que hacer con ella. Esto es lo que me ha dado que pensar. De ahi que el peso que puedan tener no proviene fundamentalmente de la agudeza de su conceptualización, sino de la realidad experienciada. La conceptualización, sin embargo, es necesaria, y en ella me ha influido decisivamente I. Ellacuría, de quien citaré largamente y a quien le vi luchar durante dieciséis arios, en teoria y práctica, con el problema de la violencia, siempre volcado a introducir el máximo de racionalidad en el uso de tan peligrosa realidad?

Estas reflexiones son también crisrianas, con lo cual queremos decir algo mís que una obviedad o repetir rutinariamente y sin dialéctica verdades conocidas: "la violencia no es evangélica", "Jesús no hizo uso de las armas", "hay que poner la otra mejilla"... Aqur hablamos más bien desde la convicción contrastada con la realidad y constatada en la realidad - de que lo evangélico del cristianismo tiene mucho que aportar a vivir con espíritu adecuado en tiempo de violencia, y de que puede aportar algunas cosas importantes mejor que otras ideologías y prácticas. Esto me lo iluminó -y creo que le iluminó a Ignacio Ellacuria - la figura de Monsefior Romero, quien no fue un pacifista a ultranza, pero dio un ejemplo de cómo con la inspiración cristiana se puede y debe trabajar en una situación sumamente violenta para tomarla en shalom, en paz.

Por úllimo, estas reflexiones se hacen en vistas a la espiritualidad, no puramente en vistas a la ética o la política. Pero hay que aclarar que con ello no nos estamos introduciendo en absoluto en el nebuloso mundo de lo invisible e intocable en contraposición a lo histórico, pues por espiritualidad entendemos el modo de dejamos afectar activamente por la realidad histórica -en este caso, la violencia-, el modo de afrontarla y el modo de confrontarla. 
A continuación vamos a hacer algunas rellexiones, sólo algunas -de las muchas que pudieran hacerse-, y de forma fragmentaria, y las vamos a exponer en forma de breves proposiciones. Seleccionamos las que más nos han impactado en este proceso: (1) hay que minimizar los males de la violencia, (2) hay que maximizar los bienes que pueden generarse con ocasión de la violencia, y (3) hay que redimir la violencia

Digamos finalmente que ofrecemos estas reflexiones con la esperanza de que puedan servir no sólo en liempos de violencia, sino también en tiempos de paz, esperanza que no creemos ingenua porque en tiempos violentos, aunque sub specie contrarii, aflora también la realidad en su totalidad, con todas sus limitaciones y wadas sus potencialidades.

\section{Minimizar los males de la violencia}

Primera proposicion: La única forma de humanizar en verdad la violencia es ponerle fin, pero, mientras dura, el hwnonizarla exige un serio esfuerzo tebrico y práxico para mantenerla dentro de proporciones. Esto es logro del espíritu y es expresión de honradez con lo real.

Según la fe cristiana, la violencia siempre está relacionada con algún tipo de mal, de modo que si en este mundo no hubiera pecado no habría violencia, lo cual debiera bastar para exigir sobriedad ante la violencia y no exaltarla de ningún modo, como suele ser frecuente en la historia en movimientos entusiásticos. Pero además de la relación que la violencia tiene con el mal, ella es en si misma un mal por los graves males fisicos que intende en directo y otros graves males que la acompartan con necesidad histórica.

Aceptar esto, aparentemente tan obvio, y sacar la obvia conclusión de que a la violencia - sea cuales fueren las pérdidas y ganancias para los bandos- hay que ponerle fin cuanto antes es la primera exigencia al espíritu humano. Lo que ocurre es que muchas veces - ciertamente en el tercer mundo- la violencia de respuesta se hace historicamente inevitable, y por ello se puede pasar por alto lo que tiene de grave mal. Por ello, la primera afirmación sobre la violencia, ciertamente sobre la violencia originante, pero también sobre la violencia de respuesta. es que constituye un grave mal. Y recordarlo no es superfluo, al menos a un nivel existencial, cuando nos encontramos en medio de un conflicto. Así lo expresó Ignacio Ellacuria:

La lucha armada es siempre un mal, mayor de lo que se piensa, que sólo puede ser permisivemente utilizado cuando con seguridad se van a evitar males maycres... Desde un punto de vista realista, es inevitable, incluso para el cristiano, aceptar ciertas formas de violencia, segin los principios y cautelas que antes se han expuesto, siempre que se trate de una violencia liberadora no terrorista referida sobre todo a la liberación de la muerte que se abate

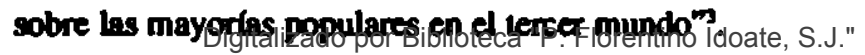

Universidad Centroamericana José Simeón Cañas 
I. Ellacuría no fue un pacifista a ultranza y sintió en su came -lo llewó lasta el martirio- la injusta pobreza, la opresión y la represión de los pobres, y or ello defendió teóricamente la posibilidad de una violencia revolucionaria egítima. Sin embargo, simultáneamente mantuvo y recalcó los males de la vioencia y que con esos males hay que acabar cuanto antes. Por ello trato de poner in al conflicto cuanto antes, y mientras duró se desvivió por racionalizar al náximo el uso de la violencia (en su estadio de inevitablidad y aun de legitimilad) para minimizar sus males.

a) Para racionalizar al máximo el uso de la violencia -es decir para minimizarla y, así, humanizarla-, Ellacuría estableció el principio fundamental de la proporcionalidad.

Esto nos lleva al problema de la proporcionalidad. Si a uno le quitan un diente no tiene derecho en su defensa a quilar un ojo. La vida material sólo puede ser quitada cuando estŕ en juego la vida material. En el caso de la violencia revolucionaria... se trata de defender la vida material de una inmensa mayoria... Pero poner en peligro la vida material, sobre todo la de las mayorías pobres y necesitadas, por objetivos que desbordan la salvaguarda de esa vida material no está justificado. Algunos piensan que la libertad, la propiedad, la identidad cultural, elc., son más valiosos que la vida material, pero nada hay más originante y sustentante que la vida como posibilidad fundamental de cualquier otro valor. En general, el principio de proporcionalidad fundamental sostiene que los bienes culturales se consigan y se defiendan por medios culturales, los políticos por medios polílicos, los religiosos por medios religiosos, etc. Quitar la vida a otro no guarda proporción con objetivos éunicos-culturales, clasistas o políticos. Esto es tanto más ciento cuando más se den condiciones para conseguir esos objetivos por sus medios proporcionadost.

Ellacuría trató, pues, de desarrollar criterios de racionalización para el uso de la violencia, pero lo que aquí nos interesa recalcar es que lo hizo no en directo por hacer avanzar teóricamente la discusión ética sobre la guerra, sino afectado hondamente por la tragedia y ajustado a la realidad. A esto es a lo que llamamos una re-acción del espíritu ante la realidad histórica. En este caso, la búsqueda de minimizar, racionalizando al máximo, el uso de la violencia es el primer paso aunque parezca pequeño y alejado de utopías pacifistas- de la espiritualidad en tiempos de violencia.

b) Y desde aquí —desde la espiritualidad- habría que comprender, en nuesura opinión, la lógica más profunda actuante en la lamada doctrina tradicional sobre la guerra justa, que también fue recogida fácticamente por Ellacuría. Lo más importante de ella es la confesión implícita de que la guerra siempre es un mal, y de ahí la decisión de buscar condiciones para minimizarla. El que la finalidad sea justa es ciertamente esencial desde la perspectiva ética, pero al

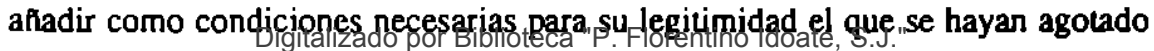


los medios no bćlicos, la posibilidad de que la guerra tenga éxito y el que no traiga mayores males se está reconociendo la seria necesidad de autocontrol aun antes de aceptar la violencia en esa situación límites, autocontrol que es ante todo acto del espíritu para humanizar una tuágica situación.

Tcorizar sobre la violencia para eliminarla o, al menos, para minimizarla es la primera expresión de la cspiritualidad. En la persona de Ignacio Ellacuría la guerra causó un gran impacıo como mal real. Y ese mal real para todos, sobre todo para las mayorias, es lo que movilizó su espíritu para ponerle fin. En la práctica, cl personaje Ellacuría propició diálogos y negociaciones entre las partes, propició el debate nacional y la creación de una tercera fuerza (incomprendida, en gencral, por la izquierda) para acelerar el fin de la guerra, dialogó innumerables veces con unos y con ouros. Y en la teoría, el intelectual Ellacuría desarrolló nuevas tcsis sobre la violencia para humanizarla y minimizarla.

En cste sentido, es irónico que a Ellacuría le hayan acusado de violento algunos bienpensantes, siendo así que buscó en teoría y en práctica minimizar la violencia. Lo que no acaban de entender sus detractores es que no es más pacífico quien "condena la violencia venga de venga" que quien trata de minimizarla realista e históricamente, que es lo que ćl hizo. $O$, por decirlo de otra forma, que no es más pacífico el que con desidia y rutina repite slogans anti-violencia o incluso cita a Gandhi o al Nuevo Testamento en favor de un pacifismo a ultranza que el Ellacuría que, con rabajo y crearividad, traló de minimizarla hasta llegar a ponerle fin. $Y$, por supuesto, que no es más pacífico quien no se introduce y denuncia con claridad la violencia originaria del sistema que el Ellacuria que denunció y cargó con esa violencia. Y si hablamos ahora de la persona, no sólo del personaje e intelectual Ellacuria, es para mostrar que todo su trabajo durante esos años fue ante todo expresión de su espiritualidad.

A todo esto pudiera objetarse que se tratn aquí de mínimos - minimización de la violencia - micntras que apelar al espíritu parece que debiera hacerse para tareas más altas. Pero para quien está cncarnado en la conflictividad real de la historia -y recordemos que la encarnación y no el mero ser espectador es acto primordial del espíritu- esos mínimos son máximos. En cualquier caso, el autocontrol, la racionalización y minimización al máximo del uso de la violencia es exigencia primaria que se impone al espíritu humano.

La conclusión es que, resumiéndolo en palabras irónicas, pero penetrantes, del mismo Ellacuría, si de violencia se trata "sólo los pacifistas debieran hacer las guerras". Es decir, todo cuidado en su utilización es poco ante los males que produce. Y esto, que tan claramente se percibe en tiempo de guerra, debiera ser igualmente claro en tiempo de paz: hay que terminar con o minimizar la muerte lenta que causa la injusta pobreza. Parafraseando a Ellacuría, pudiéramos decir - también utópicamente- que "sólo los empobrecidos debieran planificar la economia".

Digitalizado por Biblioteca "P. Florentino Idoate, S.J."

Universidad Centroamericana José Simeón Cañas 
Segunda proposición: Aun en el caso de que la violencia llegase a ser legirima nunca debe convertirse en mistica, sino que hay que luchar activamente contra los subproductos deshumanizantes que produce históricamente.

Monsevior Romero, en su tercera carta pastoral de 1978 Iglesia y organizaiones políticas populares, aun aceptando en principio la posible legitimidad de la violencia en una situación como la salvadoreña, denunció lo siguiente:

Estŕ haciendo mucho mal a nuestro pueblo esa violencia fanática que casi se hace "mística" o "religión" de algunos grupos o individuos. Endiosan la violencia como fuente única de justicia y la propugnan y practican como método para implantar la justicia en el país. Esa mentalidad patológica hace imposible detener la espiral de la violencia y colabora a la polarización de los grupos humanos'.

Con estas palabras, Monseñor Romero describía un hecho repetidamente zonstatable: además del mal directo que produce la violencia, ésta lleva en sí nisma una dinámica deshumanizante que produce otros muchos males.

a) Ante todo, la violencia suele generar un dinamismo a mayor y más cruel jolencia, que normalmente toma la forma de terrorismo. Sea cuales fueren los reneficios militares o políticos, de acuerdo con su propia definición terrorismo is lo que se practica para "alerrorizar" a otros, es decir, no es un uso posiblenente legítimo de la fuerza para autodefenderse o para destruir al enemigo nilitar en cuanto tal. Por ello, no tiene en modo alguno un significado de "de"ensa propia", aun en el sentido más lato, o de vencer bélicamente sobre el idversario en cuanto tal. De ahí el juicio de Ellacurfa:

Todas las formas de terrorismo, sobre todo las que acarrean la muerte o (un atentado a) la integridad fisica o psíquica de las personas; el terrorismo, definido como el uso de la violencia sobre lodo física contra personas indefensas, sean civiles o no, con el objeto de aterrorizar es siempre reprobable, tanto más reprobable cuanto sea mayor el daño infligido y la indefensión de la víclima?.

El terrorismo viene definido, por lo tanto, por lo que se hace, no por quién lo lace, y por ello en El Salvador, aunque la parte gubernamental ha definido zomo terrorismo casi siempre el accionar militar del FMLN, de hecho esa parle ;ubemamental es la que más abundante y cruelmente ha caído en él, aunque ambién el FMLN hizo uso de prácticas terroristas, sobre todo al asesinar alcalles y a ideslogos de la oposición. En cualquier caso lo que hay que condenar, ıquí sí, "venga de donde venga", sin excepción, es el terrorismo por absolulanente injusto y deshumanizante. 
La conclusión es que si hay que esforzarse en el autocontrol, teórico y práctico, de lo "militar-bélico", mucho más hay que hacerlo con lo "terrorista" que debe ser claramente denunciado y no condonado por nada. Ellacuría entró en una larga discusión teórica sobre el uso de las minas y sobre la distinción entra "bomba-en-un-coche" y "coche-bomba", lo cual por cierto le trajo graves ataques y acusaciones. Pero lo importante, de nuevo, es que su esfuerzo teórico estaba dirigido, por una parte, a que no se definiese como terrorista lo que fuese sólo bélico-militar, y en ese sentido, para defender al FMLN cuando era injustamente acusado de terrorismo; pero, por otra, también para acusar de terrorismo -desde criterios objetivos- al FMLN cuando cometía actos terroristas. Y eso, porque sea cuales fueren sus ventajas militares y políticas a corto plazo, a mcdiano y largo plazo el terrorismo de cualquier lado deshumaniza a una sociedad que se haya edificado sobre él.

b) La mística de la violencia tiende también a militarizar la toralidad de la realidad, personal y social, y a subordinar cualquier otra dimensión (económica, social, cultural, sindical, religiosa, familiar, personal) a lo militar. $Y$ aunque en determinados momentos esto pueda ser comprensible, la realidad pronto se cobra venganza, simplemente porque los seres humanos no somos así. Se da, pues, un empobrecimiento reductor y uлa deshumanización contra los que hay que luchar activamente.

Las formas que toma esta militarización son variadas, y vamos a mencionar sólo dos de las más importantes, tal como han aparecido en el conflicto salvadorefio:

* Suele absolutizarse lo militar al presentarlo como la forma más radical y el grado más elevado de compromiso - al cual habrá que supeditar cualquier otro, lo que lleva a ignorar, minusvalorar o despreciar - cuando no a ridiculizarotras formas de lucha liberadora, aceptadas a lo sumo como pasos previos secundarios y buenos sólo si se relacionan con lo bélico, todo lo cual puede ir acompañado además de un complejo de radicalismo propio y de superioridad élica sobre los demás.

A esto hay que responder que, si es cierto que no se puede excluir a priori que lo militar pueda ser también fuente -y en El Salvador lo ha sido- de valores y pueda ser incluso expresión de amor, no hay que presuponerlo con facilidad, ni en teoría ni en la práctica, ni sobre todo hay que errar en el criterio para juzgar en qué consiste la máxima radicalidad. En nuestra opinión, ésta no consiste en la máxima capacidad de destrucción del adversario -aun con los grandes riesgos personales que ello conlleva-, sino en la máxima expresión de amor, sin que con esto queramos caer en palabreria piadosa. $Y$ en este sentido, bueno será reflexionar por qué Monseñor Romero llegó a ser no sólo la ligura más querida del país, sino también la tenida por más radical, incluso por muchos miembros del FMLN N Y Ya razón está en lo siguiente: unos, con su lucha y los 
riesgos que corren por esa causa, pueden mostrar amor al pueblo, pero pueden también mostrar —al menos concomilantemente - amor a sí mismos y a su propia organización. Lo que es extremadamente raro es ver a alguien que muestra amor a la gente y sólo amor. Y eso es precisamente lo que hizo Monseñor Romero, quien arriesgó todo, su vida personal por supuesto, pero también su "organización" (la Iglesia insitucional) por el bien de la gente, y de esa forma mostró amor y sólo amor. Con lo cual queremos decir que para decidir dónde se da la máxima radicalidad no hay que lijarse tanto en el medio de lucha (si son las armas, o la palabra prolética, o el trabajo político, educativo...), sino en el amor real e histórico que se hace presente a través de cualquier medio de lucha. $Y$ eso es tanto más verdadero cuando, como en el caso salvadoreño, los riesgos que dan credibilidad al amor acompañan no sólo a la lucha armada, sino a cualquier tipo de lucha, aun la más alcjada de la lucha armada, como lue la de Monseñor Romero.

* La militarización suele aparecer también en el exagerado verticalismo según el cual la vanguardia dirigente, apelando sobre todo a las necesidades de la guerra, habla y decide en nombre de un pueblo, lo cual es un error y una injusticia. Y suele expresarse también en la manipulación hasta de lo religioso, lo cual no sólo es injusto, sino poco político, pues ello empobrece los procesos y los priva de la eficacia de lo religioso.

c) Por último, la mística de la violencia suele llevar no sólo a la aceptación, sino a la exaltación de la violencia, personal, grupal, nacionalmente... y eso es deshumanizante. Por muy acostumbrados que estemos a ello, hay que estar en contra de que la historia de los pueblos (incluida la del pueblo de Israel y, análogamentc, la de la Iglesia) se enseñe alrededor de batallas, y de que según les haya ido en ellas los pueblos podrán celebrar o no. Es indudable que al recordar esas batallas se podrán celebrar liberaciones de yugos injustos -aunque también suelen celebrarse imposiciones de tales yugos-, se podrá celebrar el valor, la creatividad, la astucia..., pero no se deberá ignorar que esas celebraciones están basadas sobre la sangre de muchos seres humanos. ( $Y$ hablando de exaltación de la violencia, no estará de más recordar que buena parte de la industria del cine y de la televisión está montada en muy buena medida sobre dicha exaltación).

A esto hay que añadir que la exaltación de la violencia no sólo celebra actividades bélicas en que mueren seres humanos — del bando propio y del ajeno-, sino que introyecta y hace crecer hasta el desprecio la visión del "otro" como irreconciliablemente otro, distinto, adversario, antagónico y muchas veces despreciable, cuyo sufrimiento, muerte y destrucción, por ser del otro, no parece ser ningún mal especial. ( $Y$ eso sin llegar a casos patológicos, como el que aparece en la película Paton, cuando el general, tras una batalla y contemplando la desolación causada, dice: Forgive me, God, but / love it).

Digitalizado por Biblioteca "P. Florentino Idoate, S.J."

Universidad Centroamericana José Simeón Cañas 
Es psicológicamente comprensible que se celebre la desaparición de un adversario, responsable de torturas, barbaries y masacres contra el bando propio, sobre todo cuando ha actuado criminalmente en contra de niños, mujeres y ancianos indefensos - bien lo sabemos en El Salvador con las masacres de El Sumpul, El Mozote, El Junquillo... Pero hay que recordar que entre la mayoría de los seres humanos que suelen luchar y matarse entre sí —en El Salvador, campesinos en uno y otro bando- hay mucha más semejanza que diferencia. En el caso salvadoreño, Monseffor Romero, de nuevo, Jo dijo con loda claridad:

Tampoco podemos ignorar, aun sin entrar en mayores detalles, el trágico espectáculo que se está ofreciendo, en el país, entre organizaciones fundamentalmente integradas por campesinos y campesinas que luchan entre sí y que últimamente están en pugna violenta. Lo más grave es que no son únicamente o fundamentalmente- ideologras las que han logrado desunirlas y enfrentarlas. No es que los miembros de estas organizaciones piensen en su mayoria de forma distinta sobre la paz, sobre el trabajo, sobre la familia. Lo más grave es que a nuestra genle del campo la está desuniendo precisamente aquello que la une más profundamente: la misma pobreza, la misma necesidad de sobrevivir, de poder dar algo a sus hijos, de poder llevar pan, educación, salud a sus hogares'.

Según las formas que toma la violencia y las razones para ello variará el tipo de confrontación dentro de la familia humana, por supuesto, pero en todas cllas hay merma grave de la conciencia fundamental de ser familia humana. Por ello, exaltar la violencia es - se sepa o no- ir contra la propia carne, y es por ello deshumanizante. A algunos no les gustará hacer de la "Yamilia humana" lo último, y preferirán encontrar eso último en la parria, la raza, la culura, la lengua, la Iglesia, la religión, realidades todas importantes, sin ninguna duda. Y se podrá discutir teóricamente en dónde haya que poner lo último - si es que se lo quiere poner en algún lugar. En mi opinión, la respuesta es dialéctica, por supuesto. Por un lado, la ultimidad sólo puede expresarse a través de lo concreto, pero eso concreto sólo puede ser tenido como último en cuanto es expresión de humanidad y no de ninguna otra cosa.

La conclusión de lodo este apartado es mínima, pero nos parece decisiva: la violencia produce males físicos directos, pero tiende también a producir como por necesidad otros males físicos y morales: terrorismo, militarismo, desprecio absoluto al otro... Vivir la violencia con espíritu significa entonces ser honrado con lo real, reconocer lo terrible de estas cosas y no escamotearlas, juzgarlas como deshumanizantes para todos y hacer contra todo ello. En cualquier caso, lo que nunca se debe hacer es caer en la mistica de la violencia y ensalzarla.

En una de sus últimas intervenciones públicas, Ellacurla se expresó contra ta mistica de la violencia con estas palabras, de nuevo irónicas y vigorosas: "Al dar los partes de guerra, ambos bandos debieran decir. llorando les comunicaUniversidad Centroamericana José Simeón Cañas 
mos que nos hemos visto obligados a infligir tantas bajas al adversario...".

Espiritualidad es entonces superar esa mística de la violencia, con sus analogías en tiempos de paz. Es superar el terrorismo, la tendencia a no poner límites al ejercicio del poder, que en tiempo de paz suele transformarse en corrupción. Es superar el dogmatismo, la exigencia a ulıranza de disciplina y el verticalismo, hasta cierto punto necesarios para el accionar militar, pero que vuelven difícil la democracia y la fraternidad una vez terminado el conflicto. Es superar la dinámica de generar, aumentar y exaltar la diferencia, la oposición, el desprecio al otro, que, por serlo, suele ser llamado "criminal", "esbirro" en tiempo de guerra, o "perro", "negro", "indio"... en tiempo de paz. Todo esto es absolutamente deshumanizante en tiempo de guerra y perdura en ticmpo de paz. Destruye físicamente la "especie humana", y destruye antropológicamente la noción misma de "familia humana". En esa mística hay un profundo principio de deshumanización. Espiritualidad cs, entonces, la lucha por superarlo.

\section{Maximizar los bienes que acaecen con ocasión de la violencia}

Tercera proposición: La violencia de respuesta, por trágica que sea, puede ser expresión de amor a un pueblo y puede producir subproductos positivos, entre otros el de desenmascarar la mentira con que se encubre la violencia originante y el de exigir la lucha por otros medios-contra la injusticia.

Por honradez con lo real, hay que reconocer que con ocasión de la violencia se producen también bienes imporantes, que, además, por la naturaleza del asunto, suelen disminuir en tiempos de paz. Este hecho - que pudiera ser interpretado en analogía con el felix culpa - es algo reconocido y constatable, y no sólo exacerbación conceptual dialéctica o intento desesperado de hacer de la necesidad virtud. $Y$ es que a través de y en contra de la negatividad surge también lo positivo. Veámoslo en tres realidades importantes - cuya relación con la violencia es de diversa índole-, tal como han aparecido en el conflicto salvadorefio.

a) La realidad da que la violencia de respuesta puede ser en si misma expresión de amor, es decir, de lo más positivo del ser humano, amor que puede desencadenarse como reacción a lo terrible y espantoso de la violencia originante?. La argumentación téórica más radical en favor de esa posibilidad ya la dio santo Tomas al reconocer que los combatientes pueden incluso ser mártires si han dado su vida por amor, pues el amor es el elemento formal que otorga excelencia al martirio' ${ }^{10}$.

Cuánto de justicia han buscado los combatientes y cuánto de amor han mostrado al optar por la lucha armada y sus obvios riesgos, sólo Dios lo sabe, pero no se puede cerrar esa posibilidad ni negar que la motivación de algunos o de muchos de ellos sea la de liberar a su pueblo. En la realidad hay en lodo esto un más y un menos, Boftanifuestor Asf entre las, muchas cosas quye pueden mover a 
la lucha armada, puede estar la desesperación que genera la pobreza o el desco de venganza, pero también puede serlo el amor. Puede ser también que la motivación del amor esté más presente en los comienzos que cuando la guerra se ha convertido en trágica rutina, en campesinos que han tomado las armas para que el pueblo pueda vivir que en quienes, además, buscan el triunfo de un partido... La casuistica es, pues, compleja y delicada, pero lo que no se puede excluir es que haya combatientes que han sido movidos por el amor", y pensamos que los ha habido ciertamente en las revoluciones nicaragüense y salvadorcina. Y hay que recordar, además, que junto a otras razones políticas - probablemente más decisivas-, también ha podido estar actuante el amor en la decisión de poner lin al conficto de manera negociada por razones humanitarias, en último término. por amor.

Cuánto hay, pues, de gracia y cuánto de pecado en las revoluciones, en último término sólo Dios lo sabe. Con cuánto cuidado haya que usar lo religioso para no animar a guerras ni martirios, hay que tenerlo siempre presentc, dada la innala icndencia de lo religioso a la radicalización de lodas las áreas de la existencia, incluida la gucrra. Pero dicho esto, no se puede ignorar quc, a su modo, muchos han combatido por transformar una sociedad cruel e inhumana en una sociedad más justa y humana. Por ello - ya que, además, siguen siendo difamados por algunos aun después de muertos ${ }^{12}$ - bueno será admitir la posibilidad de que algunos pucdan ser llamados mártires del reino de Dios. Quede al menos este consuelo a sus familiares que no han podido encontrarlos y enterrarlos, y que ya no pueden recuperarlos.

b) Además de que la violencia pueda ser expresión - trágica_ de amor, con ocasión de ella se han conseguido varios bienes importantes, y uno de ellos es el de desenmascarar la mentira y llamar la atención a la verdad de la realidad. La violencia de respuesta es, cierlamente, violencia, pero hay que recalcar también que se trata de una respuesta a una situación inhumana que genera víclimas en forma mayoritaria y cruel. Recordémoslo muy resumidamente.

Antes de la muerte rápida de la violencia se da la muerte lenta de la pobreza, producto de la injusticia, verdadera "violencia institucionalizada". Para mantener la pobreza de los muchos que enriquece a los pocos, éstos desencadenan la violencia originante, llevada a cabo por ejércitos, cuerpos de seguridad y escuadrones de la muerte a su servicio, de modo que la realidad se toma en "el imperio del infierno", como decía Monseffor Romero. Y en respuesta a esa doble violencia suele acaecer la violencia revolucionaria. Lo que hay que afiadir a esto tan sabido es que el mundo de la abundancia no suele darse por enterado de la muerte lenta de la pobreza ni de la violencia institucionalizada, y solo parece hacerlo o cuando estalla la muerte violenta en forma inaudita llevada a cabo por las derechas (asesinatos como el de Monsentor Romero, el de las religiosas norteamericanas, el de los jesuitas de la UCA) o cuando se da la reacción bélica revolucionaria.

Digitalizado por Biblioteca "P. Florentino Idoate, S.J."

Universidad Centroamericana José Simeón Cañas 
Con ser trágico, pues, los conflictos violentos son los que normalmente haen inocultable la injusticia originante, de modo que se pueda empezar a tener oticia de su verdadera realidad. Triste - y afortunadamente- estos conflictos on los que desenmascaran el escándalo primario de la realidad y los que llevan preguntamos por sus causas. Los conflictos violentos son los que desenmascain la mentira, los que sacan a luz lo ignorado y encubierto, los que liberan a la erdad del encubrimiento al que la someten. Y eso es un gran bien.

Antes de la represión y de la guerras, Nicaragua o El Salvador, por cjemplo, ran países desconocidos, como lo sigue siendo Haití, una vez pasadas las escaunuzas, o lo es el Tchad o los 300 millones de pobres de solemnidad en la idia, y un muy largo etcétera. Tristemente, son sólo los conflictos los que arecen tener suficiente fuerza para sacudir un poco el egoísmo institucioalizado en los países de abundancia y superar el encubrimiento al que están umetidos de diversas maneras los pueblos pobres: en los medios de comunicaín, en la política exterior, en la indiferencia activamente presente tras la leologización de la tolerancia y de la posmodernidad, en el silenciamiento de is cuestionamientos del socialismo pasado y las alabanzas del neo-liberalismo resente... Todo es bueno para mantener en silencio o volver a relegar al sileno a los pueblos crucificados.

En esta situnción de pretendida e hipócrila ignorancia, los conflictos produin al menos este gran bien: des-enmascarar, des-ignorar, des-tranquilizar... En nguaje cristiano, la cruz de los conflictos se conviene en juicio y condena del undo. Y en lenguaje de I. Ellacuría se convierte en pregunta para todos: "qué smos hecho para que estos pueblos estén crucilicados y qué vamos a hacer ira bajarlos de la cruz".

c) La violencia de respuesta expresa trágicamente la necesidad de que hay le seguir respondiendo a la injusticia, es decir, de proseguir -aunque de otra rma- la lucha contra la injusticia. Esto hay que recalcarlo porque en el esente se alaba y se receta a todos - con mejor o peor intención- actitudes : diálogo y tolerancia, los valores de la paz, la democracia, el progreso, es 'cir, actitudes y valores de los que está ausente todo lo que pueda ser conflicto praxis conflictiva. Aunque en esto hay mucho de bueno $-y$ ojalá hubiese ucho de real-, hay que puntualizar algunas cosas:

En primer lugar, la realidad es la que sigue siendo conflictiva y antagónica. or mucho que se pretenda hacer desaparecer del lenguaje términos como "justia" e "injusticia", "opresión" y "liberación", éstos son todavía insustituibles ura describir adecuadamente nuestro mundo y sus necesidades, y sin ellos lo ıcubrimos una vez más. Por mucho que se pretenda introyectar en la conciena colectiva que la mejor solución para el mundo es dejarlo a la dinámica actual ipuesta por el norte, las estadísticas y la experiencia cotidiana lo contradicen. I realidad histórica de nuestro mundo sigue siendo en si misma conflictiva Universidad Centroamericana José Simeón Cañas 
porque sigue produciendo graves antagonismos entre empobrecedores y empobrecidos. Por mucho que se quiera ocultar, la parábola del rico Epulón y del pobre Lázaro sigue reflejando nuestra situación a cabalidad.

En segundo lugar, el hecho mismo del conficto ayuda a mantener la concepción "agonista" - luchadora - que le es esencial a la existencia humana, la cual ojalá llegue a exprearse en formas diferentes a la del confliclo armado, por supuesto, pero sin que esto quite un ápice de necesidad a la lucha Dicho en palabras sencillas, en El Salvador, y terminada la guerra, en nada ha desaparecido la necesidad de luchar contra la mentira y el encubrimiento, la corrupción y la hipocresía sociales, y nada digarnos de la urgencia de luchar contra la injusticia... En otras palabras, los pasos, grandes o pequefios, que dan los pueblos pobres no son en ningún modo regalo de los poderosos, sino logro a través de luchas y conflictos. Y esto, tan simple, pero que quiere ser encubierto, debe ser mantenido.

En tercer lugar, el conflicto ayuda a mantener la estructura dialéctica y aun duélica de la fe cristiana. En ella, las realidades positivas siempre son descritas en relación y contradicción a otras negativas: Dios e fdolos, Cristo y anticristo, reino y antirreino, gracia y pecado... No es esto buscar de antemano la conflictividad, sino mínima honradez con la esencia de la revelación de Dios y de la fe cristiana. A la misma fe, pues, le compete por esencia introducirse en la conflictividad.

Con todo esto queremos recalcar la necesidad de mantener la "lucha" en la delinición del ser humano y del ser cristiano, y recalcar que una de las cosas que quieren quitar a los pueblos del tercer mundo es precisamente eso: su demostrada capacidad de lucha. Dicho con mayor generalidad, quieren acabar con lo especílicamente novedoso que aportan los pueblos del tercer mundo y quieren silenciar a aquellos pueblos que mejor han expresado la esperanza y la necesidad de luchar para ponerla a producir:

Aquellos paises que han levantado la esperanza de algo nuevo, como Nicaragua y El Salvador de los ochenta, necesitaban ser no sólo destruidos sino desacreditados y convertidos en una espúrea esperanza de pueblos románticos porque rompian el proceso de homogeneización iniciado con la era Reagan. La geo-cultura de la desesperanza y la teologfa de la inevitabilidad requieren hoy una proyección global para permitir la homogeneización de la nueva reestructuración promovida por la élite del poder global. La desesperanza es la actitud necesaria para la estabilidad desde la perspectiva del dominador ${ }^{13}$.

Amor, verdad, necesidad de lucha y esperanza son, pues, realidades positivas del espíritu que se hacen presentes con ocasión del conflicto. Digamos para terminar este apartado que todo ello sigue siendo necesario en tiempos de paz, y Digitalizado por Biblioteca "P. Florentino Idoate, S.J."

Universidad Centroamericana José Simeón Cañas 
que lo es en un punto específico: mantener el horizontc de la utopía, dejarse mover por ella y encaminarse, aunque sea en pasos muy pequeños, hacia ella. El primer mundo no sólo receta sobriedad, sino que ha declarado la muerte de la utopía. Recela tolcrancia, pero cae (inconsciente o planificadamente) en la indiferencia. La alabada ausencia de conflictos mucho nos tememos que esté entre ouras cosas - al servicio de hacer morir las utopías de los pobres. Y eso no se puede tolerar.

Los pobres, los que no dan la vida por supuesto, siguen teniendo una utopía, y la tienen por necesidad porque esa utopía no es oura cosa que la vida, la posibilidad de supervivencia. Lo que ocurre es que hasta eso se les niega, y, por ello, los pobres expresan en su misma realidad, a la vez, la necesidad de utopía y de lucha. En otras palabras, la utopía es un concepto que expresa "sentido", en este caso "esperanza", pero es también un concepto "práxico", que lleva consigo la exigencia a ser realizado. En el tercer mundo, la lucha esłá al servicio de la utopía y la utopía --lo que no ha lugar, pero que ha de llegar a tener lugar, pues se trata de la vida - exige lucha. Utopía y lucha son correlativos, y al queremos quitar el espíritu de lucha nos quieren quitar también la utopía.

Para que se nos entienda bien, recordemos al terminar este apartado lo dicho anics. La violencia como lucha armada es un mal, genera muchos males y por ello dcbe ser erradicada. Pero eso no quila el que exprese la necesidad de lucha en el tercer mundo. Una lucha que se deberá llevar a cabo a través de las "armas" específicas de cada institución o movimiento social (iglesias, universidades, sindicatos, partidos politicos, medios de comunicación social...) y que ojalá nunca tenga que ser llevada a cabo con armas bélicas, pero que es, al lín y al cabo, lucha en un mundo en el que lo que está arriba, sean los podcrosos, sea el norte, sigue oprimiendo a los que están abajo.

Lo que esto significa en términos de espiritualidad es sencillo: no se puede ser humano ni cristiano en el mundo actual sin responder y re-accionar a la injusticia y violencia originantes. No hay que caer, por lo tanto, en la trampa de la "inevilablidad" que nos tienden por doquier, como si, aunque no vivamos en el mejor de los mundos, sí vivimos en el único mundo posible, y por lo tanto sería ilusorio e inútil intentar luchar contra él. Ante esto, lo que hay que hacer es mantener el espíritu de misericordia consecuente, atender a los heridos en el camino y luchar contra los salteadores que siguen omnipresentes.

\section{La redención de la violencia: Ios mártires}

Cuarla proposición: Lo más específicamente cristiano es redimir la violencia. Eso sólo ocurre cuando se la erradica, pero para lograrlo no sólo hay que luchar contra ello desde fuera, sino que hay que cargar con ella desde deniro. Eso - y el hacerlo por amor a las víctimas- es lo que ejemplifican los márires. Ellos son los que pueden reveriir la dinámicg de la violencia.

Universidad Centroamericana José Simeón Cañas 
Todo lo anteriormente dicho expresa ya muchas convicciones cristianas, pero podemos preguntarnos si hay algo más especílicamente cristiano en relación con la violencia, y así es como lo describe Ellacuría:

Parcecría que desde un punto de vista más cristiano, el de la perfección en el seguimicnto del Jesús histórico, los cristianos reduplicativamente cristianos en su ser y en su actuar, siendo los primcros y más arriesgados en combatir toda forma de injusticia, no deberian hacer uso de la violencia. No es que la violencia sea siempre y en todos los casos rechazable para un crisliano, pero cl cristiano en cuanto tal no da ordinarimente su testimonio específico a través de la violencia. No es tampoco que se quiera dejar el trabajo "sucio" a ouros, mientras que el cristiano se queda entre los "puros" que no se ensucian las manos. Se urata más bien de dar de la manera más cabal y plena testimonio de que la vida csú sobre la mucrte, de que el amor está sobre cl odio. Tal actitud seria aceptable y clicaz si es que ese mismo cristiano se atreviera hasta el martirio en la defensa de los más pobres y en cl combate conura los opresores con el testimonio de su palabra y de su vida ${ }^{14}$.

Con estas palabras, Ellacuría quiso expresar lo más cspecílicamente cristiano ante la violencia, y además intentó elaborar ante sus posibles críticos más "belicisıas" lo que pudiéramos llamar una "apología" de la "violencia no-armada". Para ello afirmó ures cosas: a) que el cristiano tiene que estar dispuesto a combatir toda forma de injusticia y a defender a los más pobres en contra de los opresores, b) que para combatir prefiere usar medios que en sí mismos expresen la supremacía de la vida sobre la muerte y del amor sobre el odio, y c) que para tener credibilidad en todo ello los cristianos tienen que ser "los primeros y más arriesgados", tienen que atreverse "hasta el martirio".

Ellacuría nos remite en último término a la disponibilidad al martirio por causa de la justicia como acuitud cristiana ante la violencia. De ello y su significado hablaremos más adelante, pero ahora, para poder comprender a Ellacuría, quien sólo pudo escribir lo anterior en presencia de mártires reales, y para constatar la masividad del lenómeno, masividad que es la que permite elaborar una teoría y no sólo reflexiones piadosas anecdóticas, vamos a enumerar una letanía de mártires, aunque para ello cambiemos por un momento el estilo de estas reflexiones. $Y$ lo hacemos también por agradecimiento y para mantener viva su memoria ahora que en cl país ha terminado la guerra.

a) En El Salvador hay muchos, como Jesús, márires por el reino de Dios: personas que han defendido a los pobres y a las vícumas, que por ello se han enfrentado a ia injusticia y violencia originantes, que han luchado contra ellas con armas no-bélicas, y que libre e indefensamente han sido asesinadas por todo ello.

En este sentido, mártires son, ante todo, los campesinos, cllos y ellas, por

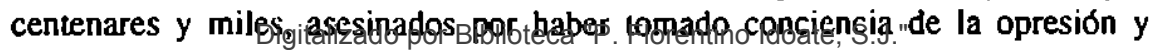


aberse organizado para liberarse de ella, por ser delegados de la palabra o por ner una Biblia o una estampa de Monseffor Romero. Mártires son los obreros c las ciudades, asesinados por manifestarse contra la injusticia de sus salarios y I inhumanidad de ser usados como fría mercancía. Mártires son los sindicalisis, sacados de sus casas, asesinados o desaparecidos. Mártires son los miemros de las organizaciones populares, masacrados en las calles en la maniГestaión del 22 de enero de 1980 y en tantas ouras. En una palabra, mártires son uchos hombres y mujeres pobres, las mayorías populares, asesinados porque an luchado sin armas, pero con toda justicia para dejar de serlo y por haberlo echo - los creyentes - en nombre del evangelio.

Junto a ellos, y por defenderlos a ellos, mártires son también innumerables studiantes, maestros de primaria y secundaria, profesores de universidad, que on releido la historia del país, han enseñado su verdad y sus causas. Mártires on médicos que, fieles al juramento de Hipócrates y a la parábola del buen imaritano, han sido asesinados por curar en sus campamentos a los tenidos por ibversivos o - con increible crueldad-cuando los atendían en sus consultoos de la ciudad. Mártires son periodistas, salvadoreños y extranjeros, que han tografiado con sus cámaras y han transcrito en sus cuadernos la realidad berrante del país. Mártires son abogados, jueces, miembros de instituciones de erechos humanos, como Marianella García Villa y Herber Anaya Sanabria, ue han denunciado y desenmascarado aberraciones y masacres. Márlires son umbién algunas personas, pocas, muy pocas, de las clases pudientes, como nrique Alvarez, que acompañan y contrastan con miles de humildes trabajadois y trabajadoras como Julia Elba y Celina.

Mártires son también hombres y mujeres de Iglesia, seminaristas como unaro Cáceres, catequistas como Ticha, delegados de la palabra como Jesús, sligiosas como Silvia y como las cuatro hermanas norteamericanas, Ita, Maura, rorothy y Jean, el don más preciado del pueblo de Estados Unidos a El Salvaor. Mártires son sacerdotes cercanos al pueblo, desde Rutilio Grande y Alfonso lavarro hasta el P. López y López, humilde trabajador de Fe y Alegría, pasando or Neto Barrera, Octavio Ortiz, Rafael Palacios, Alirio Macías, Cosme pezotto, Manuel A. Reyes, Emesto Abrego, Marcial Serrano. Mártires son rcliiosos, teólogos e intelectuales, como los tan recordados Ignacio Ellacuría, .mando López, Juan Ramón Moreno, Segundo Montes, Nacho Martín Baró, sesinados por poner la ciencia -que suele enriquecer a los ricos- al servicio e los pobres. Pastor, profeta y mártir es, finalmente, Monseñor Romero, caso isolito en la historia de la Iglesia, arzobispo asesinado sobre el altar cuando elebraba la eucaristía, pero no por defender privilegios o derechos de la Iglesia, ino - coma Jesús- por defender la vida y los derechos del pueblo pobre.

Junto a estos mártires más conocidos, que de una u otra forma nos recuerdan Jesús por su enfrentamiento con los poderosos y su defensa activa de los Digitalizado por Biblioteca "P. Florentino Idoate, S.J."

Universidad Centroamericana José Simeón Cañas 
pobres, están los innumerables mártires anónimos, niffos, mujeres y ancianos en su mayoria, cuyo delito fundamental ha sido ser pobres, vivir en zonas confliclivas - "estanque que debía ser secado, es decir aniquilado, para poder agarrar al pez - y ser usados como ejemplo para que otros escarmienten, para que no tomen conciencia, no se organicen y queden aterrorizados. Estos son hoy el siervo doliente de Yahvé, el pueblo crucificado, como decían Monseffor Romero y el padre Ellacuría. Son los que en total inocencia e indefensión, sin liberlad siquiera para rehuí la muerte, han cargado sobre sf el pecado del mundo - la muerte lenta de la pobreza y la muerte violenta de la represion- y son los que han quedado destruidos por ese pecado.

Mártires son, entonces, entre muchos otros miles, los campesinos de La Cayetana y Tres Calles, asesinados en 1975, y los campesinos de Aguilares, ciudad ocupada militarmente en mayo de 1977, donde los soldados profanaron el cuerpo de Cristo en el sanlísimo sacramento y el Cuerpo de Cristo en la historia, asesinando a decenas de campesinos. Mártires son los centenares de muertos en el Sumpul, atrapados entre el ejército salvadoretio y hondurefio, asesinados por ambos ejércitos y ahogados muchos de ellos al tener que lanzarse al ro. Mártires son los centenares de campesinos de El Mozole, asesinados los varones en la Iglesia, los niños en una casa y las mujeres en otra, pudiendo oír desde donde estaban el llanto de sus hijos. Mártires son los campesinos asesinados en Las Hojas y encontrados meses después botados en un pozo. Mártires son los masacrados en San Francisco Guajoyo, en El Junquillo, en San Sebastián, en El Calabozo, de todo lo cual dan buena cuenta los relatos espeluznantes del Informe de la Comisión de la verdad.

Mártires podemos llamar tambiên a tantas mujeres que siguen buscando hasta el día de hoy a sus hijos, esposos, padres y hermanos desaparecidos. Mártires son, afiadamos simbolicamente a una lista que sería interminable, las docenas de personas que murieron baleadas o asfixiadas en la plaza de catedral el 30 de marzo de 1980, precisamente cuando se celebraba el entierro de Monsefior Romero.

Esta es la nube de testigos del pueblo salvadoreño. Suelen decimos a veces que al recalcar tanto el martirio rozamos el masoquismo o, que sin querer, fomentamos el fanatismo. Pero pudiendo haber en estas críticas algo de verdad, es también verdad, y mayor verdad, que estos mártires son un bien y producen el bien.

b) En primer lugar y ante todo, en estos mártires se verifica la intuición cristiana de que para redimir el pecado hay que cargar con ell, afirmación fundamental que hace el Antiguo Testamento al presentar al siervo doliente de Yahvé y el Nuevo Testamento a Cristo crucificado. En otras palabras, también al pecado en general y a la violencia en particular puede aplicarse la antigua sentencia de los padres de la Iglesia: quod nos est assumptum nos est Universidad Centroamericana José Simeón Cañas 
edemptum. Y, en concepualización más actual (René Girard), se necesitan acos fundantes anti-violentos para frenar y revertir la dinámica pan-violenta de la salidad.

Según esto, la postura del cristianismo ante la erradicación de la violencia es oble: por un parte, la violencia debe ser combatida desde fuera con toda sucrte e armas (muy preferentemente no-bélicas) externas a ella, pero, por otra, para renar y revertir su dinamismo originante, hay que cargar con ella desde dentro. usí puede ser interprelada, como parece hacerlo Pablo, la cruz de Jesús: como contecimiento que revierte el dinamismo de la violencia, porque deja —dicho n palabras metalóricas - que ésta desahogue toda su fuerza en Jesús hasta uedarse ella sin fuerza.

Pues bien, los mártires son los que cargan hoy con la violencia. Cierlo es que nos ofrecen, además, cl combate frontal contra ella por medios pastorales, sin'icalcs, universitarios, elc., aunque en la hora decisiva esos medios no-violentos o les libren de la muerte que preven y asumen con libertad. Otros cargan más lirecta y tolalmente con clla, los masacrados indefensamente, que ni siquiera ienen libertad para rehuir la mucre.

Cuánta eficacia histórica tengan estos márúres para revertir el dinamismo de a violencia es cosa a analizar. Pero, a priori según la fe cristiana, hay que Cirmar que ellos son los que cargan con la violencia y su pecaminosidad. Y a osteriori hay que decir - véase el caso salvadoreño- que ellos son los que nás han contribuido a acelerar la linalización de la violencia armada.

En segundo lugar, estos mártires introducen realidades y valores en la realilad histórica que hacen contra la violencia originante, la injusticia egoisla y la nentira encubridora, y de esa forma, como el siervo y como Cristo crucificado, raen salvación y luz.

Nada puede reemplazar a los mártires para captar lo más hondo de nuesura calidad, para tener aquella "aprehensión primordial de realidad" de la que, en enguaje zubiriano, hablaba Ellacuría, pues, como él mismo decía en lenguaje nás sencillo, "en los pueblos crucificados, como en un espejo invertido, podenos conocer todos lo que somos por lo que producimos". Los mártires hacen ransparente la realidad, la que hemos sufrido en el pasado reciente y la que ransformando radicalmente el presente- debe existir en el futuro.

Los mártires son los que en una sociedad egoísta introducen misericordia; os que en una sociedad de víctimas y verdugos inuroducen reconciliación; los jue en una sociedad injusta, en que campea la violencia institucionalizada, inroducen justicia y paz. Y los mártires son en la tradición cristiana, y en el mejor entido común de la humanidad, los que introducen amor.

En una sociedad violenta, muchos mueren generosamente, pero para precisar

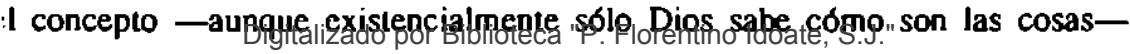
Universidad Centroamericana José Simeón Cañas 
hay que distinguir entre caídos y mártires. Los héroes caídos ofrecen generosidad de vida y beneficios en favor de la causa por la que fueron matados. En ese sentido pueden ser signos de amor "a lo suyo", entendido aqui "lo suyo" no en forma necesaria ni principalmente egoísta, sino como realidad abierta a otros. Los mártires, por su parte, son expresión pura y simple del amor, de amor real y verdadero, y de amor no a la propia institución (organización, universidad, sindicato, Iglesia) sino, en directo, de amor en principio a "todos", de amor que quiere humanizar a todos, incluidos los verdugos. Desde este punto de vista, los mártires no son sólo ni primariamente signos de lo propio, sino de lo universal. Su muerte no es, en directo - como puede interpretrarse la de los caídos-, una llamada a seguir la lucha (violenta), sino a trabajar, luchar y amar con radicalidad.

Por último, los mártires, son a la vez don de Dios a nuestro pueblo y ofrenda agradable que desde nuestro país sube hasta el cielo. Es éste un gran misterio, pero que debe ser mantenido creyentemente, pues de otra forma vano será proclamar una fe surgida de un crucificado - y por ello es también incomprensible que Santo Domingo haya ignorado activamente a los mártires latinoamericanos.

Jesús es a la vez sacramento y camino a Dios, y ese Jesús, en ésa su doble realidad, tiene su cuerpo en la historia. Entre nosotros, salvadorefios, "el Divino Salvador" no es sólo paurón y nombre del país, sino que muchos salvadoreños lo hacen presente en sus vidas y en sus muertes. Y Jesús, digámoslo al menos para consuelo de los familiares y amigos que les han sobrevivido, los hace la máxima expresión de su presencia en la historia. Por ello, recordemos para terminar unas palabras de Ireneo de Lyon, teólogo, obispo, santo y mártir a su vez, del siglo II sobre los mártires y sobre toda sangre justa derramada:

Si no hubiera de ser derramada la sangre de los justos, de ninguna forma hubiera el Señor tenido que derramar sangre. Que desde el principio liene voz la sangre, dijóselo Dios a Caín luego que había asesinado a su hermano... Todo esto indicaba la recapitulación de la sangre de los justos y profetas vertida desde el principio, la cual habría de tener lugar en su persona.

El clamor de la sangre de los mártires salvadoreños ha llegado hasta Dios, y el mismo Cristo ha recogido y asumido esa sangre en la suya propia, para que - por decirlo en lenguaje cristiano- nada del valor de todas aquellas sangres quede perdido, sino que quede ganado para siempre. $Y$, a la inversa, la cruz del pueblo y la sangre de los mártires es lo que sigue haciendo presente la sangre y la cruz de Jesús en la historia.

Esto es lo que sigue generando verdad, amor, justicia y esperanza. Ese es el dinamismo que se ofrece para revertir la historia de la violencia y redimirla. Esa disponibilidad de luchar y amar la justicia y la vida de los pobres hasta el final -aunque ese final llegue a ser martirial_, eso es espiritualidad.

Digitalizado por Biblioteca "P. Florentino Idoate, S.J."

Universidad Centroamericana José Simeón Cañas 


\section{Notas}

1. Le terrible maldad de la violencia del sistema puede arreciarse para el caso de El Salvador en el reciente informe de la Comisión de la verdad, publicado en ECA 533 (1993) 159-323.

2. Véase su escrito "Violencia y cruz", en Teologla polaica (San Salvador 1973) 95-127, y su artículo. publicado poco antes de su asesinato, "Trabajo no violento por la paz y violencia liberedora", Concilium 215 (1988) 85-94.

3. Ibid., 88.93.

4. Ibid., 92.

5. Volviendo al caso de El Salvedor, recuerdo que en 1980 la situación era tan trágica que se veía venir inevitablemente la respuesta amada del FMLN. Ellacuría escribió por entonces sobre una posible solución político-militar al conflicto, con lo cual venía a decir que la guerra de respuesta del FMLN era inevitable y, en aquellas circunstancias, legrima, aumque acompaĩada de una búsqueda de solución también polítiea. Pero en euanto fracasó la ofensiva final de enero de 1981, escribió y comenzo a trabajar en seguida - recuerdo que to hizo ya en febrero de ese mismo ario- en la solución negociada. Nada tiene que ver con veleidades ese cambio de actitud, sino con un riguroso dejarse afectar por la realidad y responder con espíritu a sus exigencias. Y eso fue de hecho una puesta en práctica de la doctrina tradicional: aunque la causa pueda llegar a ser jusin, hay que atender a sus posibilidades de txito y a que no produzca mayores males. Y hay que usar, aunque fuese simultáneamente, de medios pacíficos para (evitarla o) ponerle fin, es decir, díalogo y negociación.

6. Varios, La vor de los $\sin v o z$, San Salvador (1981) 118.

7. Op. cis., 93.

8. Op.cis.,100.

9. Para el caso salvadoreño recomendamos vivamente la lectura del ya citado Informe de la Cornisión de la verdad. En él aparece no sólo maldad, sino la maldad cornplexiva de militares, paramilitares, escuadrones de la muerte, aparato de justicie, más sus ráces en la oligarquía civil, el gobiemo salvadoretio, la embajada de Estados Unidos... Es espeluznante, pero es necesario para comprender la violencia de respuesta, dejarse afectar por la magritud de la inquided.

10. ST II-I, q. 124, a 2, ad 2. En orro lugar dice que "padece por Cristo no s6́lo el que padece por la fe en Cristo, sino también el que padece por cualquier obra de justicia", In Ep. ad Rom, c.VII, lect.7.

11. En El Salvador esto es mucho más elero de los combatientos del FMLN que de los del ejtrcito oficial, pero tempoco se puede excluir el que algunos de ésios hayen luchedo y entregado su vida pensando que hacím un bien al pais.

12. Una de las recomendaciones del Informe de la Comisión de la verdad es precisamente "el reconocimiento de la honorabilidad de las víctimas", op. cui. 322.

13. X. Gorostiaga, "La mediación de las ciencias sociales y los cambios internacionales", en J. Comblin, J. I. González Faus, J. Sobrino, Cambio sacial y pensamiento cristiano an America batina (Madrid 1992) 131.

14. Op. cis., 94. 